\title{
Gastrointestinal manifestations of postnatal cytomegalovirus infection in infants admitted to a neonatal intensive care unit over a five year period
}

\author{
J L Y Cheong, F M Cowan, N Modi
}

Arch Dis Child Fetal Neonatal Ed 2004;89:F367-F369. doi: 10.1136/adc.2003.032821

\begin{abstract}
Sixteen cases of postnatal cytomegalovirus (CMV) infection were identified in a neonatal intensive care unit population over a five year period. Eleven of these infants had gastrointestinal signs at the time of presentation. These ranged from minor and transient (abdominal distension and enteral feed intolerance) to severe and life threatening (protein losing enteropathy, diarrhoea, and hypernatraemic dehydration). An initial diagnosis of necrotising enterocolitis was common, but no infant showed intestinal or hepatic portal pneumatosis. The gestational age of the infants was 24-38 weeks. All had received fresh maternal breast milk. It is suggested that CMV enteritis is added to the spectrum of clinical manifestations of postnatal CMV infection. Signs suggestive of necrotising enterocolitis with atypical features should prompt investigations for CMV infection.
\end{abstract}

$\mathrm{P}$ ostnatal cytomegalovirus (CMV) infection has not attracted the attention received by congenital infection as it is held to result in low morbidity. The recognition of severe gastrointestinal symptoms in a small number of preterm infants with postnatal CMV infection prompted a search of the literature and a review of infants admitted to our neonatal unit over a five year period who were known to have postnatally acquired CMV infection.

\section{METHODS}

Infants were identified as a result of CMV screening in the presence of symptoms such as prolonged jaundice, unexplained enteritis, or signs of systemic sepsis in the absence of positive blood cultures for bacterial sepsis. The standard screen test was the urine CMV DEAFF (detection of early antigen fluorescent foci) test. This is a rapid culture test whereby early CMV antigens are detected by immunofluorescence after the inoculum on a cell sheet is spun for two to four days. The diagnosis of CMV infection was based on the fact that a previously negative urine CMV DEAFF test became positive coincidentally with the onset of clinical symptoms. Urine CMV DEAFF screening of infants at admission was not performed routinely although many of the infants had early screening. However, all of our cases had negative urine CMV DEAFF tests before the positive tests. In cases where the symptomatology was severe, additional tests such as CMV blood IgM and antigen detection were carried out. As the infants were sick preterm babies, it was not feasible to obtain gastrointestinal biopsy samples to confirm the diagnosis of CMV gastrointestinal disease.

Our unit feeding policy is to start enteral feeds early once the infant is clinically stable. The preference is for the mother's own breast milk. If not available, then with parental consent, banked breast milk is given. The mother's own milk is given fresh within 48 hours of expression. This milk would have been stored at $4^{\circ} \mathrm{C}$. If fresh mother's milk is unavailable or insufficient, frozen maternal breast milk or banked donor milk is used. Our unit has its own milk bank on site. Milk is obtained from donors who are screened for a panel of viruses (hepatitis B, hepatitis C, HIV-1 and HIV-2, human T cell leukaemia/lymphoma virus type I or II, and syphilis.). The milk is pasteurised (heated to $62.5^{\circ} \mathrm{C}$ for 30 minutes) and then frozen at $-20^{\circ} \mathrm{C}$.

\section{RESULTS}

Sixteen infants were identified out of 2830 admissions to the Queen Charlotte's and Chelsea and Hammersmith Hospital neonatal unit over a five year period.. They ranged from a median age of 25 weeks (24-29) and median birth weight of $801 \mathrm{~g}$ (705-978) (values in parentheses are interquartile ranges). All infants had received fresh maternal expressed breast milk before the onset of symptoms, and, at the time of diagnosis, were receiving a combination of fresh maternal expressed breast milk and banked breast milk. Maternal CMV serostatus was not available for all infants.

Table 1 shows basic data and clinical characteristics of the cases. The infant in case 2 received ganciclovir from day 32 until 44. There was no appreciable improvement of his clinical status that could be attributed to the antiviral treatment. His gastrointestinal symptoms subsequently resolved and he was eventually discharged home. He now has developmental delay.

Table 2 shows the identified cases as a percentage of admissions in gestational age groups. Two of the infants died (cases 5 and 11).

\section{DISCUSSION}

During the past decade, developments in the diagnosis and management of CMV infection and disease have led to refinements in the definitions of "infection" and "disease" in an attempt to develop consistent reporting in clinical trials. "CMV infection" is defined as the isolation of the CMV virus or detection of viral proteins or nucleic acid in any body fluid or tissue specimen. "CMV disease", or more specifically in the case of "CMV gastrointestinal disease", the definition encompasses clinical symptoms from the upper and lower gastrointestinal tract, findings of macroscopic mucosal lesions on endoscopy, and demonstration of CMV infection in a gastrointestinal tract biopsy specimen. ${ }^{1}$ These definitions were developed primarily for the transplant population and may not be applicable to a newborn population. In particular, it is not a feasible option to perform endoscopy and obtain biopsy specimens on premature newborns without an open

Abbreviations: CMV, cytomegalovirus; DEAFF, detection of early antigen fluorescent foci; NEC, necrotising enterocolitis; PCR, polymerase chain reaction 
Table 1 Details of the 16 cases of cytomegalovirus (CMV) infection identified over a five year period

\begin{tabular}{|c|c|c|c|c|c|c|c|c|}
\hline Case & Sex & GA & BW & Neg test & CMV test & Other positive tests & Symptom onset & Symptoms \\
\hline 1 & $\mathrm{~F}$ & 29 & 890 & 3 & 65 & - & 64 & Diarrhoea, NEC \\
\hline 2 & M & 24 & 550 & 10 & 27 & ETA (27) & 25 & $\begin{array}{l}\text { Diarrhoea, abdominal distension, protein losing } \\
\text { enteropathy, pleural effusions, treated with } \\
\text { ganciclovir }\end{array}$ \\
\hline 3 & $\mathrm{~F}$ & 25 & 730 & 2 & 37 & Blood lgM (37) & 37 & $\begin{array}{l}\text { No abdominal symptoms, lethargy, } \\
\text { thrombocytopenia }\end{array}$ \\
\hline 4 & $\mathrm{~F}$ & 38 & 2220 & 35 & 120 & $\begin{array}{l}\text { NPA (37) } \\
\text { Blood lgM (113) }\end{array}$ & 113 & $\begin{array}{l}\text { Diarrhoea, abnormal LFT, Rothmund-Thompson } \\
\text { syndrome }\end{array}$ \\
\hline 5 & M & 23 & 580 & 13 & 98 & Blood lgM (91) & 90 & Diarrhoea, dehydration, died \\
\hline 6 & $\mathrm{~F}$ & 27 & 1010 & 3 & 61 & - & 56 & $\begin{array}{l}\text { Vomiting, abdominal distension, abnormal LFT, } \\
\text { neutropenia }\end{array}$ \\
\hline 7 & M & 25 & 908 & 1 & 35 & - & 30 & Diarrhoea, NEC, hepatitis \\
\hline 8 & M & 29 & 1485 & 2 & 61 & - & 60 & No abdominal symptoms \\
\hline 9 & $\mathrm{~F}$ & 29 & 1130 & 2 & 48 & - & 45 & No abdominal symptoms \\
\hline 10 & M & 32 & 978 & 3 & 80 & - & 70 & Diarrhoea \\
\hline 11 & $\mathrm{~F}$ & 25 & 642 & 2 & 56 & ETA (80) & 40 & NEC, died \\
\hline 12 & $\mathrm{~F}$ & 24 & 715 & 55 & 66 & $\begin{array}{l}\text { ETA (65) } \\
\text { Blood antigen }(75) \\
\text { Blood } \lg M(80)\end{array}$ & 60 & Diarrhoea, NEC \\
\hline 13 & M & 24 & 775 & 1 & 105 & - & 103 & No abdominal symptoms, lethargy \\
\hline 14 & M & 25 & 908 & 1 & 45 & - & 42 & No abdominal symptoms, lethargy \\
\hline 15 & M & 24 & 705 & 5 & 66 & - & 66 & No abdominal symptoms, lethargy \\
\hline 16 & $\mathrm{~F}$ & 24 & 801 & 3 & 67 & - & 60 & Severe GOR requiring fundoplication, abnormal LFT \\
\hline
\end{tabular}

F, Female; M, Male; GA, gestational age in completed weeks; BW, birth weight in grams; Neg test, last negative urine CMV DEAFF test; CMV test, CMV urine DEAFF test (day of first positive test); DEAFF, detection of early antigen fluorescent foci; Other positive tests, other CMV tests (day of first positive test); ETA, endotracheal aspirate; Symptom onset, day of symptom onset; LFT, liver function tests; NEC, necrotising enterocolitis; GOR, Gastro-oesophageal reflux.

laparotomy. The differentiation between intrauterine and early postnatal CMV infection is also difficult. We have noted a temporal association between onset of clinical symptomatology with a first positive urine CMV DEAFF test, after a previous negative urine test. Where available, we have also presented the results of other CMV tests. Ideally, it would have been best to have obtained a urine CMV DEAFF test shortly after admission. This was only available in 12 of our 16 cases, as routine testing on admission was not unit practice at the time. In five of the cases, there was a lag time of more than seven days between onset of symptoms and a positive urine CMV DEAFF test because the CMV test was performed as a second line investigation after the first line of investigations had proven to be negative.

We identified 16 infants $(0.57 \%$ of all admissions $)$ with postnatal CMV infection over a five year period. However, the true prevalence is likely to be much higher as DEAFF testing was selective and only when prompted by clinical signs. Transfused blood is no longer likely to be a route of infection, as blood products for neonates are prepared from CMV negative donors and are leucocyte depleted. In contrast, the risk of acquisition of postnatal CMV infection from breast milk may be substantial. Hamprecht et $a l^{2}$ conducted a three year prospective study of the transmission of CMV from mother to preterm infant by breast milk. They found that 73 of 76 breast feeding CMV seropositive mothers developed virus re-activation. The mother to infant transmission rate was $37 \%(27 / 73)$, resulting in postnatal infection in 33 of

\begin{tabular}{lll}
$\begin{array}{l}\text { Table } 2 \\
\text { admissions in gestational age groups }\end{array}$ & \multicolumn{2}{c}{ Identified cases as a percentage of } \\
\hline $\begin{array}{l}\text { Gestational age } \\
\text { (weeks) }\end{array}$ & No cases & $\begin{array}{l}\text { Percentage of total } \\
\text { admissions for } \\
\text { gestational age group }\end{array}$ \\
\hline $23-27$ & 10 & 3 \\
$27-31$ & 4 & 1 \\
$31-35$ & 1 & 0.2 \\
$>35$ & 1 & 0.1 \\
\hline
\end{tabular}

their 87 preterm infants (38\%). Seventeen (52\%) of the 33 preterm infants were asymptomatic, 16 had symptomatic infection, and four infants developed sepsis-like symptoms. Two of the infants with sepsis-like symptoms required reintubation, but all of the observed symptoms resolved spontaneously, and no infant died.

In each case identified in our study, CMV screening was undertaken as part of the investigation of jaundice, or signs of sepsis in the absence of positive bacterial cultures. Seven of the 16 babies had severe diarrhoea during the time of CMV infection. Of these, one had a severe protein losing enteropathy and one developed severe acute hypernatraemic dehydration and subsequently died. In four infants, the initial diagnosis was that of necrotising enterocolitis (NEC) because of the presence of abdominal distension, tenderness, and fresh blood staining of the stools. However, no infant had radiological evidence of intramural or hepatic portal pneumatosis, and in none of these cases was NEC subsequently confirmed.

CMV enteritis with ischaemic necrosis is common and well recognised in patients with AIDS $^{3}$ and in immunosuppressed transplant patients. The spectrum of gastrointestinal involvement in this patient group includes oesophageal, gastric, small intestinal, and colonic disease ${ }^{4}$ as well as cholangitis and pancreatitis. ${ }^{5}$ Clinical manifestations include abdominal pain, watery diarrhoea, gastrointestinal bleeding, ${ }^{6}$ vomiting, ${ }^{7}$ and protein losing enteropathy. ${ }^{8}$ Small bowel perforation may occur. ${ }^{9}{ }^{10}$ Dolgin et $a l^{11}$ described a case of CMV enteritis in a child with AIDS resulting in massive haemorrhage and fatal small bowel obstruction. At laparotomy, large yellow plaques with central ulceration were found along the entire small bowel. Smith et al ${ }^{12}$ reported on two infants with extensive leiomyolysis due to CMV enterocolitis in association with HIV infection.

We identified only a single published report of CMV enteritis in the newborn. ${ }^{13}$ This described a $2.2 \mathrm{~kg}$ neonate who presented with a diagnosis of NEC. These authors refer to four additional reports of neonatal CMV enteritis in the non-English language literature.

The preterm neonate is an immunocompromised host, and therefore the common observation of clinically significant 
gastrointestinal signs during postnatal CMV infection, probably acquired enterally in fresh maternal breast milk, is not surprising. This does not, however, appear to be a recognised manifestation of postnatal CMV infection. Diagnosis is likely to be difficult, and recognition requires a high index of suspicion. Kusne et $a l^{14}$ showed that the specificity and sensitivity of a polymerase chain reaction (PCR) technique was better than diagnosis of CMV enteritis based on histopathology, shell viral assay, and tube culture of intestinal biopsy specimens. In any case, intestinal biopsy, other than at laparotomy, is unlikely to be widely applicable in the preterm population. However, it might be of interest to evaluate intestinal biopsy specimens taken at surgery in infants with NEC to see if some have CMV enteritis. There has been a report of the value of negative CMV PCR from stool specimens taken from immunocompromised adults in ruling out intestinal CMV disease. ${ }^{15}$ The authors did caution that this method required further evaluation with testing of larger numbers of patients with AIDS. Stool testing was unfortunately not performed in our patients, and, so far, is not advocated routinely as a confirmatory test of CMV in the neonatal population. ${ }^{16}$

The examination of maternal CMV serological status to assess the risk of CMV transmission to the infant is controversial. Current practice is to recommend and promote the use of mother's own fresh milk. Although studies have shown that freezing breast milk at $-20^{\circ} \mathrm{C}$ reduces $\mathrm{CMV}$ viral titres $^{17}$ and infectivity, ${ }^{18}$ there is the disadvantage of delay in introduction of enteral feeds. A recent report describes a low prevalence of postnatal CMV acquisition in a neonatal unit where it was policy to freeze breast milk before administration to the infant. ${ }^{19}$ The minimum duration of freezing was not included in the report. There is a balance between the risk of CMV acquisition from fresh breast milk and the benefits of early introduction of enteral feeds. Early initiation of enteral feeds has been shown to reduce the total duration of parenteral nutrition, promote gastrointestinal development, and improve overall tolerance of feeds. ${ }^{20-22}$ Clarification of best practice with regard to maternal CMV testing and handling of expressed breast milk will require prospective evaluation.

All our infants except one were premature, with a skewed distribution towards the extremely preterm gestational age range. The exception was a 38 week female infant with Rothmund-Thomson syndrome. This is an autosomal recessive syndrome with poikilodermatous skin changes, photosensitivity, increased risk of skin and bone malignancies, and immunodeficiency. ${ }^{23-25}$

Treatment options in the neonate are limited. Ganciclovir has been used in congenital infection ${ }^{26}$ and infants presenting with cholestasis. ${ }^{27}$ However, there are no published controlled studies of the use of ganciclovir. Other agents such as foscarnet and cidofovir have been used in paediatric and adult immunocompromised patients. ${ }^{28} 29$ We used ganciclovir in one of our patients who was systemically very unwell, and clinical improvement that could be attributed to the antiviral treatment was unclear.

Our experience shows that the clinical signs range from minor and transient to severe and life threatening. We suggest that a diagnosis of "atypical necrotising enterocolitis" or diarrhoea, abdominal distension, abdominal tenderness, and the passage of blood stained stools in the absence of radiological features of NEC should prompt a consideration of enterically acquired CMV infection in the preterm baby.

\section{ACKNOWLEDGEMENTS}

We thank Emily Boland for her contribution to this study.

\section{Authors' affiliations}

J L Y Cheong, F M Cowan, N Modi, Department of Paediatrics, Division of Paediatrics, Obstetrics and Gynaecology, Faculty of Medicine, Chelsea and Westminster Hospital, Imperial College, London, UK

Correspondence to: Dr Modi, Department of Paediatrics, Division of Paediatrics, Obstetrics and Gynaecology, Faculty of Medicine, Imperial College, 369 Fulham Road, London SW10 9NH, UK; n.modi@imperial. ac.uk

Accepted 27 November 2003

\section{REFERENCES}

1 Ljungman P, Griffiths P, Paya C. Definitions of cytomegalovirus infection and disease in transplant patients. Clin Infect Dis 2002;34:1094-7.

2 Hamprecht K, Maschmann J, Vochem M, et al. Epidemiology of transmission of cytomegalovirus from mother to preterm infant by breasffeeding. Lancet 2001;357:513-18.

3 Haller JO, Cohen HL. Gastrointestinal manifestations of AIDS in children. AJR Am J Roentgenol 1994; 162:387-93.

4 Page MJ, Dreese JC, Poritz LS, et al. Cytomegalovirus enteritis: a highly lethal condition requiring early detection and intervention. Dis Colon Rectum 1998;41:619-23.

5 Teixidor HS, Honig CL, Norsoph E, et al. Cytomegalovirus infection of the alimentary canal: radiologic findings with pathologic correlation. Radiology 1987;163:317-23.

6 Zupancic JA, Pennie RA, Issenman R. Intussuception in a child with cytomegalovirus infection. Pediatr Infect Dis J 1994;13:548-9.

7 Ahn JH, Le JH, Lee KH, et al. Successful treatment with ganciclovir for cytomegalovirus duodenitis following allogeneic bone marrow transplantation. Korean J Intern Med 1999;14:91-4.

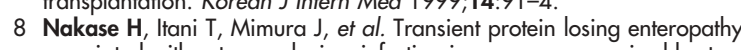
associated with cytomegalovirus infection in a non-compromised host: a case report. Am J Gastroenterol 1998;93:1005-6.

9 Huang YC, Lin TY, Huang CS, et al. Ileal perforation caused by congenital prenatal cytomegalovirus infection. J Pediatr 1996;129:931-4.

10 Chamberlain RS, Atkins S, Saini N, et al. Ileal perforation caused by cytomegalovirus infection in a critically ill adult. J Clin Gastroenterol 2000;30:432-5.

11 Dolgin SE, Larsen JG, Shah KD, et al. CMV enteritis causing haemorrhage and obstruction in an infant with AIDS. J Pediatr Surg 1990;25:696-8.

12 Smith VV, Williams AJ, Novelli V, et al. Extensive enteric leiomyolysis due to cytomegalovirus enterocolitis in vertically acquired human immunodeficiency virus infection in infants. Pediatr Dev Pathol 2000;3:591-6.

13 Reyes C, Pereira S, Warden MJ, et al. Cytomegalovirus enteritis in a premature infant. J Pediatr Surg 1997;32:1545-7.

14 Kusne S, Manez R, Frye BL, et al. Use of DNA amplification for diagnosis of cytomegalovirus enteritis after intestinal transplantation. Gastroenterology 1997;112:1121-8.

15 Michel D, Marre E, Hampl W, et al. Intestinal cytomegalovirus disease in immunocompromised patients may be ruled out by search for cytomegalovirus DNA in stool samples. J Clin Microbiol 1995;33:3064-7.

16 American Academy of Pediatrics. CMV Infection. In: Pickering LK, ed. Red book: 2003 report of the Committee on Infectious Diseases, 26th ed. Elk Grove Village, IL: American Academy of Pediatrics, 2003:260.

17 Friis $\mathrm{H}$, Andersen $\mathrm{H}$. Rate of inactivatin of cytomegalovirus in raw banked milk during storage at $-20^{\circ} \mathrm{C}$ and pasteurisation. BMJ 1982;285:1604-5.

18 Dworsky M, Stagno S, Pass R, et al. Persistence of cytomegalovirus in human milk after storage. J Pediatr 1983;101:440-3.

19 Sharland M, Khare M, Bedford-Russell A. Prevention of postnatal cytomegalovirus infection in preterm infants. Arch Dis Child Fetal Neonatal Ed 2002;86:F140.

20 Schanler RJ, Shulman RJ, Lau C, et al. Feeding strategies for premature infants: randomized trial of gastrointestinal priming and tube feeding method. Pediatrics 1999; 103:434-9.

21 Lucas A, Bloom SR, Ansley-Green A. Gut hormones and minimal feeding. Acta Paediatr Scand 1986;75:719-23.

22 McClure RJ. Trophic feeding of the preterm infant. Acta Paediatr 2001;436(suppl): 19-21.

23 Kubota M, Yasunaga M, Hashimoto $\mathrm{H}$, et al. IgG4 deficiency with RothmundThomson syndrome: a case report. Eur J Pediatr 1993;152:406-8.

24 Bellinati-Pires R, Melki SE, Colletto GM, et al. Evaluation of a fluorochrome assay for assessing the bactericidal activity of neutrophils in human phagocyte dysfunctions. J Immunol Methods 1989;119:189-96.

25 Ito T, Tokura Y, Moriwaki S, et al. Rothmund-Thomson syndrome with herpes encephalitis. Eur J Dermatol 1999;9:354-6.

26 Whitley RJ, Cloud G, Gruber W, et al. Ganciclovir treatment of symptomatic congenital cytomegalovirus infection: results of a phase II study. $J$ Infect Dis 1997; 175:1080-6.

27 Fischler B, Casswell TH, Malmborg P, et al. Ganciclovir treatment in infants with cytomegalovirus infection and cholestasis. J Pediatr Gastroenterol Nutr 2002;34:154-7.

28 Kimberlin DW. Antiviral therapy for cytomegalovirus infections in pediatric patients. Semin Pediatr Infect Dis 2002;13:22-30.

29 Khare MD, Sharland M. Cytomegalovirus treatment options in immunocompromised patients. Expert Opin Pharmacother 2001;2:1247-57. 